\title{
Danani,Claudia; Hintze, Susana (Coord.) Protecciones y desprotecciones (II). Problemas y debates de la seguridad social en la Argentina”.
}

Daniel Chao*

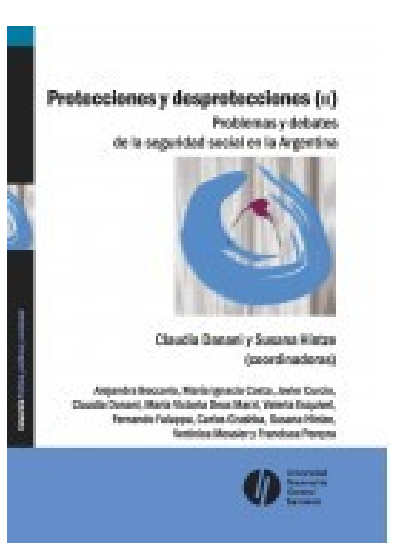

Disponible en: http://www.ungs.edu.ar/cm/uploaded files/publicaciones/649 Protecciones \%20y\%20desprotecciones\%202\%20web.pdf

Con el objetivo de examinar las transformaciones del Sistema de Seguridad Social en Argentina entre 2003 y 2013 -la denominada 'década ganada'-, el libro coordinado por Claudia Danani y Susana Hintze se presenta como una continuación de Protecciones y desprotecciones: la seguridad social en la Argentina, 1990-2010 (Ediciones UNGS, 2011), también encabezado por ambas. A través de sus ocho capítulos, el libro intenta dar cuenta de lo que las autoras llaman la "capacidad de protección" del sistema, entendida como "el atributo de políticas específicas que condensa el alcance cuanti y cualitativo de la satisfacción de necesidades de reproducción de la vida que tienen las prestaciones y servicios que se producen y circulan en tales políticas" (2014: 67). Ese

\footnotetext{
* Becario doctoral Conicet. Instituto de Investigaciones Geohistóricas (UNNE-CONICET). Correo electrónico: I.daniel.chao@gmail.com
} 
horizonte de lectura es sostenido por dos preguntas cruciales: si puede definirse una especificidad del período respecto a 'los noventa', a la par de reflexionar sobre el modo de hacer abordables las políticas públicas como objeto de estudio. El texto, resultado de un trabajo colectivo en el marco de la Universidad Nacional de General Sarmiento, presenta una mixtura de datos, lecturas, hipótesis y modos de abordaje sobre el funcionamiento estatal que lo hacen interesante como material de consulta.

Para hacer visible la capacidad de protección del Sistema de Seguridad Social argentino balancean la mirada entre la arquitectura institucional (normas, instituciones y sus dinámicas) con los efectos sobre la población de ciertas políticas específicas. En ese sentido, el libro propone centrarse en la Administración Nacional de la Seguridad Social (ANSES) como punta de lanza para entender la acción estatal en materia social. Las características institucionales y el tener bajo su órbita programas que exceden las acciones previsionales (Pensiones No Contributivas como la Asignación Universal por Hijo o programas tales como Conectar Igualdad o PRO.CRE.AR, etc.) lo convierten en la mayor agencia de política social en la etapa analizada. En esa línea, la reflexión sobre los efectos -las capacidades de protección o desprotección sobre los grupos y las personas- no puede desligarse de las características formales de la institución, en las que se incluye su trayectoria histórica. De esta forma, los distintos capítulos presentan lecturas diversas que se mueven temporalmente entre el pasado y presente de las políticas públicas de nuestro país. A su vez, esos efectos también apuntan a visibilizar el modo en que la acción estatal tensiona en la construcción de la población protegida/desprotegida a la que están dirigidas dichas políticas.

El capítulo 1 denominado "La institucionalidad de la Administración Nacional de la Seguridad Social en el Sistema de Seguridad Social argentino. Estructura organizativa y financiamiento (1991-2012)" a cargo de María Ignacia Costa, Javier Curcio y Carlos Grushka describe y caracteriza a la 
ANSES a través de la noción de "diseño institucional" entendido como el formato institucional que a la vez instituye un modo de intervención y tipos de protecciones sobre grupos y personas (2014: 19). Los autores plantean que la ANSES posee un lugar protagónico en el esquema de seguridad social y para fundamentar esa posición reconstruyen el diseño desde su creación en 1991. Hay en el desarrollo dos grandes periodizaciones que van desde el nacimiento del ente hasta 2003, donde las llamadas Leyes de Reforma del Estado establecieron conflictos respecto de la cobertura previsional, a la par que le dieron su forma de gestión 'moderna', y la segunda que se concentraría puntualmente en la ampliación paulatina de funciones que le dieron los gobiernos encabezados por Néstor Kirchner y Cristina Fernández. El análisis es muy rico en datos respecto al modo de organización y financiamiento $y$, sobre todo, en mostrar ciertas condiciones (por ej. su creciente y eficiente capacidad operativa cruzada por su uso discrecional por parte del Poder Ejecutivo) que explicarían el lugar de la ANSES como terreno de conflicto y disputas.

El funcionamiento del sistema previsional entre 2010 y 2013 es el objeto de indagación del capítulo 2 titulado “El sistema previsional: aspectos institucionales y protección, entre la transformación y la normalización". En él, Alejandra Beccaria y Claudia Danani abordan lo que denominan la “judicialización del sistema previsional", principal motor de disputas y movimiento de dicho sistema. Para las autoras, desde 2003 a 2010 el sistema previsional se "normalizó" en el sentido de que generó rutinas y sentidos que estancaron la ampliación de cobertura luego de un fuerte proceso de protección. La apuesta del capítulo es demostrar que la judicialización se convirtió en un recurso corrector o movilizador del sistema en una forma inédita. En este sentido, historizan la organización previsional argentina entre 2003 y 2010 y el papel de los estrados judiciales para afirmar que el terreno de la justicia es un nuevo escenario donde se juega la 
De Prácticas y discursos/ Universidad Nacional del Nordeste/ Centro de Estudios Sociales

Año 4, Número 5, Julio-Diciembre, 2015

ISSN 2250-6942

protección social y las discusiones sobre estatus y derechos de las personas.

Carlos Grushka es el autor del capítulo 3 denominado “Evaluación y perspectivas del Sistema Integrado Previsional Argentino" que tiene como objetivo diagnosticar al SIPA respecto a sus bases técnicas y capacidad de sustentabilidad. Para ello, el autor presenta una descripción de datos demográficos que son cruzados por las características normativas que enmarcan el sistema previsional. El capítulo presenta una primera parte donde el foco está puesto en una propuesta metodológica para definir el funcionamiento y solvencia de cualquier sistema previsional. En la segunda, se centra en las particularidades del SIPA argentino presentando aspectos del "horizonte previsional". Finalmente, articula este horizonte con datos provenientes del mercado de trabajo y las características demográficas, lo que arroja una proyección del escenario base previsional y le permite proponer alternativas al "importante deterioro en la cobertura previsional". El capítulo finaliza con un detalle del desarrollo metodológico que le permitió realizar las proyecciones.

Sobre la base de la importancia que tuvo la Asignación Universal por Hijo en la política de seguridad social de los últimos años, el capítulo 4 se centra en reconstruir el lugar histórico de las Asignaciones Familiares en nuestro país. Bajo el título “Las Asignaciones Familiares en la Argentina: de sus primeras formas a la institucionalización (1917-1991)", Fernando Falappa y Verónica Mossier abordan distintas coyunturas políticas y el papel que tuvieron las AAFF como modo de relación entre el Estado, los empresarios y los trabajadores; simultáneamente, muestran el lugar de otros actores en la discusión (la Iglesia Católica, los partidos políticos, el movimiento anarquista, etc.) que pugnaron en las disputas sobre el lugar social del obrero, las condiciones de bienestar y la seguridad social. Los autores apelan a debates parlamentarios, publicaciones de las distintas épocas y distintos documentos oficiales para armar un recorrido que lleva desde las 
primeras discusiones sobre la responsabilidad del empresariado hasta la estatización de las Cajas de AAFF en 1991. Este rearmado histórico les posibilita afirmar que las AAFF tuvieron un papel relevante en la capacidad de protección y fueron "apéndices estatales de la seguridad social" (2014: 227), a la vez que marcaron la regularidad del lugar asignado a la familia como célula básica de la sociedad.

El capítulo 5 se titula “Capacidad protectoria de la Asignación Universal por Hijo para Protección Social: problemas y debates a cuatro años de su implementación", en el cual María Ignacia Costa y Susana Hintze inscriben la $\mathrm{AUH}$ en el debate sobre la seguridad social y la asistencia como dos lógicas diferentes de intervención estatal. La pregunta que mueve gira alrededor de los fundamentos que subyacen a esta política, de qué tipo de reconocimientos se trata y qué diseño institucional hace visible. Para ello, cruzan los debates públicos -principalmente mediáticos- suscitados alrededor de la AUH, las lecturas del mundo académico al respecto y las fundamentaciones estatales de la medida a través de documentos oficiales. Para las autoras, la complejidad de la Asignación Universal por Hijo está dada en su capacidad de movilizar el Sistema de Seguridad Social hacia el reconocimiento de trabajadores informales y precarizados extendiendo los grados de protección; pero, a su vez, esa forma diferencial promueve aún más el vaivén entre asistencia-seguridad social, limita su "universalidad" y marca distancias en la adquisición de derechos.

Valeria Esquivel y Francisca Pereyra abordan en el capítulo 6 el impacto del Régimen Especial de Contrato de Trabajo para el Personal de Casas Particulares (sancionado en 2013) en las condiciones laborales del servicio doméstico argentino. Bajo el título “El servicio doméstico y sus desafíos para la protección laboral" el capítulo brinda un panorama general del sector, reconstruyendo sus características históricas y cruzando datos de la Encuesta Permanente por Hogares con entrevistas a empleadores y empleadas (ya que en su mayoría son mujeres) a fin de reflexionar sobre los 
grados de protección existentes a partir de aquel régimen de contrato. Para las autoras, modificar las condiciones del trabajo doméstico implica un cambio muy fuerte en las relaciones sociales que cruzan el problema de género con jerarquías de clase, convirtiendo al sector en un vector importante para observar la "capacidad de protección" de los últimos años. Al ser considerada una de las “ocupaciones del cuidado" (2014: 286), el empleo doméstico cruza fronteras difíciles de controlar entre la privacidad familiar y del hogar con incumplimiento de derechos laborales y situaciones de explotación. El apartado resulta muy detallista respecto a prácticas de informalidad e imaginarios sociales en esa relación de trabajo, a la par de insuficiencias estatales -sobre todo en fiscalizar el cumplimiento de la leyen el acompañamiento del ingreso al mercado de trabajo formal de ese sector.

“Protección y seguridad social de los trabajadores asociativos autogestionados" se titula el capítulo 7, en el cual María Victoria Deux Marzi y Susana Hintze recuperan el problema de la protección social a un segmento determinado de trabajadores como en el apartado anterior. En este caso, la centralidad sobre los trabajadores autogestionados está fundamentada en su heterogeneidad y en el hecho de que su expansión en los últimos años fue una respuesta política a "la incapacidad estructural del capitalismo de generar empleos para la totalidad de la fuerza de trabajo que se ofrece en el mercado" (2014: 312). El abordaje presenta una historización de las condiciones que aceleraron el surgimiento de cooperativas de trabajo y, al mismo tiempo, acerca al lector el marco normativo que regula el trabajo autogestionado y compara a la Argentina con la situación de otros Estados latinoamericanos. Asimismo, presenta los principales puntos de conflicto sobre los grados de protección social hacia el sector a través de documentos y manifestaciones de los principales organismos que los representan junto a documentos de los Ministerios de Trabajo, Empleo y Seguridad Social, y de Desarrollo Social de la Nación. En 
este sentido, el capítulo coincide con el anterior respecto a remarcar los grados de desprotección y falta de reconocimiento de derechos que todavía pesan sobre los trabajadores y trabajadoras. En el caso de los autogestionados, las principales disputas pasan por articular grados de protección diferencial sobre sujetos no asalariados lo cual implicaría ampliar la visión que se tiene sobre el trabajador.

Finalmente, el capítulo 8, denominado “Personas, instituciones y políticas. Reconstrucción y balance de la protección del Sistema de Seguridad Social en la Argentina (2010-2013)", a cargo de Claudia Danani y Susana Hintze, resulta una síntesis integradora entre el contenido del libro y las discusiones planteadas en el libro que constituye el volumen I de esta publicación, antes mencionado. Aquí, las autoras recuperan el concepto de "contrarreforma" respecto a la capacidad de protección para definir al período que va de 2003 a 2013 y diferenciarlo de años anteriores, con el cual aseguran que existe un cambio positivo en materia de Seguridad Social y mercado de trabajo. El apartado es un intento de atravesar el contenido integral del libro para mostrar la potencialidad del análisis propuesto que incorpora diseños institucionales, debates, reconstrucción histórica e imaginarios de sujetos implicados para trabajar bajo la dicotomía protegidos/desprotegidos. El capítulo finaliza con un llamado a defender la información pública como una herramienta de gobierno fundamental.

A modo de cierre, podemos decir que el libro forma parte de los numerosos debates abiertos hace algunas décadas sobre la vulnerabilidad, la exclusión y la inseguridad social en referencia a las políticas públicas y al papel del Estado. Su apuesta es, no solo presentar una lectura diacrónica y sincrónica de nuestro país, sino también mostrar caminos metodológicos que permitan hacer aprehensible las acciones políticas, sus efectos y su relación con la estructura social. A pesar de su mirada clásica hacia el Estado como regulador de la protección social -presente en autores de impacto en la perspectiva como Robert Castel- y de cierto grado de 
De Prácticas y discursos/ Universidad Nacional del Nordeste/ Centro de Estudios Sociales

Año 4, Número 5, Julio-Diciembre, 2015

homogeneidad de acción dado a este (por ej. con la noción de "contrarreforma") el trabajo coordinado por Danani y Hintze es un material potente para todos aquellos interesados en el debate sobre la Seguridad Social. Asimismo, dada la coyuntura histórica, los abordajes presentados cobran relevancia comparativa para historizar el presente y acceder a un análisis integral en materia de políticas sociales de los últimos años. 